\section{RAT BEHAVIOUR}

$\mathrm{P}$

ERHAPS the rat, more than any other animal, is to be found in the laboratories of many of the biological sciences, and it was therefore a good subject for a miscellany of papers at the symposium on "Rat Behaviour", held at Birkbeck College (University of Jondon), during July 9-10, by the Association for the Study of Animal Behaviour.

Topics covered at this symposium were: hormones and maturation, food-selection, convulsions, perceptual functions, stereotype behaviour and learning. J. T. Eayrs (Birmingham), in a paper entitled "Hormones and Central Nervous Maturation", described investigations of the functional relationships between endocrine and central nervous systems. In particular, the secretions of gonads and thyroid were varied, by ablation or injections, and behavioural concomitants studied by means of an ingenious battery of tests. In some cases, histological studies of the brain were also made ; changes in bifurcations and lengths of dendrites, as well as vascularity, were observed. Analysis of results suggested that the functioning of certain postural co-ordinating centres is accelerated by the secretion of androgens, and that this facilitatory process may extend to higher forms of behaviour. With regard to thyroid functions, it has been widely accepted that the cerebral changes associated with untreated cretinism in man are irreversible. However, rat experiments still in progress furnish evidence that replacement therapy may restore both behaviour and cortical structure to normal. Experiments with the steroid hormones support in general the hypothesis that the hormone acts on a nervous mechanism which is genetically determined and which develops independently of the endocrine organ with which it is later associated. Thyroid hormone, on the other hand, although it may facilitate the functioning of quite specific centres, exerts an influence on central nervous maturation (there is some evidence that androgens do also); it is not known whether this is a primary or secondary effect.

S. A. Barnett (Glasgow) presented a paper entitled "Problems of Food Selection in Rats", in which he classified food preferences according to whether they were common to the species (for example, in the wild rat, preference for sweet foods, avoidance of aniseed oil) or dependent on the past history of the individual. of the latter kind, experiments have shown that albino rats can usually select the nutritionally better of two foods, though past familiarity with a given food may result in its still being chosen in the presence of a better food. The development of poison shyness in wild rats was likened to the development of choices of beneficial foods. Food preferences, which are probably short-lived, may be induced by other members of the colonv ; for example, an unusual food may be brought to the nest by one rat and consumed by the others also. The choice of foods by young rats may to some extent be influenced by their tendency to orientate themselves on the mother; however, there is no evidence for detailed imitation. 'The rat's highly developed tendency to explore its environment and sample everything in it, together with its capacity for associative learning, leads to the consumption of a great diversity of foods. Dr. Barnett showed a film of experiments made on food preferences which had been lent by the Infestation Control Division of the Ministry of Agriculture and Fisheries.

M. R. A. Chance (Birmingham) read a paper on "Convulaions in the Normal Behaviour of Rodents".
The experiments reported were done mainly on mice; but there was sufficient evidence to indicate that the results might be generalized to rats. When stimuli produce convulsions in a mouse, the amount of glycogen in the brain increases. Rises in blood-sugar and injection of the anti-insulin hormone also may increase the amount of glycogen but not to the extent produced by convulsions. It was thought, then, that large increases of glycogen in the brain might indicate behaviour of a convulsive nature. These increases have been found to occur with behaviour usually considered normal. For example, the falling posture adopted by a mouse when support is removed can be shown to protect it against hacmorrhage resulting from concussion at the end of the fall. The posture occurs within a fraction of a second, and so does the glycogen increment. The rigidity of the limbs and trunk suggests that many muscles participate in maintaining the posture, and that, therefore, not only a maximal rate of discharge, but multimotorneuronal discharge may be involved. It was considered, therefore, that audiogenic hyperexcitement, including convulsions, which are usually considered abnormal, should be thought of as part of the animal's normal repertoire. It was suggested that such behaviour is a type of emergency reaction appropriate to a situation in which there is an absence of clues for a more differentiated response. In these circumstances, Peromyscus exhibits an excessive flight reaction followed by aggressive saltation and the sequence ends in cataleptic postures. The volume of evidence already brought forward to show that audiogenic seizures are likely to occur in animals with pathological conditions is not evidence in itself that this mode of discharge is always pathological ; the discharge may be thought of instead as indicating a release of the lower motor centres from cortical integration.

The three remaining papers came from psychological laboratories. I. M. L. Hunter (Oxford) summarized what is known of the role vision takes in rat behaviour. By means of extirpation experiments, it has been shown that vision is the dominant sense when a rat is learning an elevated maze, olfaction being secondary. Normal rats use both intra-maze and extra-maze visual stimuli; but the latter are especially important. In general, it appears that the rat's visual world is dominated by the more distant and more stable features of the environment. Hence in the enclosed maze, vision seems to be less important, olfaction and taction being dominant. Specially designed apparatus has been used for showing that rats are able to react to wave-length properties of red light, and that they are able to discriminate brightness, pattern and size. However, certain environmental features are more readily reacted to than others, and this has led to the suggestion that discrimination learning involves trying out a succession of 'hypotheses' until the correct one is found, that is, involves reacting now to this selected set of characteristics, now to that, learning meanwhile nothing about those characteristics 'not attended to'. Experiments have discredited this view; in general, it seems to be the entire discrimination situation to which the rat reacts. In brightness and in size discriminations, the rat may react to either the absolute or the relational features of the stimuli. It will react to relational features particularly if the stimuli resemble each other, or as a result of practice. The mechanism is not understood. It was concluded that the visual system functions most efficiently in 
spatial orientation, that is, in the discrimination of distances and directions.

R. H. J. Watson (London) read a paper on "Stereotype Behaviour in the Rat". Such behaviour is one of many kinds often called abnormal which are conveniently studied in the rat. Mr. Watson considered in detail the difficulties encountered in arriving at criteria for normality and abnormality of behaviour. He considered in particular the suggestion made by Maier that behaviour should be considered normal if it were predictable from learning theory, abnormal otherwise. Using this criterion, Maier claimed that stereotype behaviour was abnormal, instigated by frustration resulting from presenting the rats with an insoluble problem. Mr. Watson reported experiments in which a more complex insoluble problem was used and in which a more complex stereotyping resulted. The analysis of the results indicates that, both in the insoluble problem and in a subsequent soluble problem, the behaviour conformed on a number of criteria to that which would be predicted from conventional learning theory. The results also suggested that such stereotypes would be self-perpetuating.

H. B. M. Hurwitz (London) read a paper, "Response Patterns in the Rat", which was also concerned with the predictive value of learning theory. In learning theories, it is commonly assumed that the strength of a response is a function of habit strength together with drive strength. The favourite experimental devir $=f_{\text {fr }}$ investigating the roles of these two factors is the Skinner box, in which rats learn to depress a lever to obtain delivery of food in a food trough. When the habit has been learnt, food is withheld and a count made of the number of lever-pressings produced before the habit is extinguished. Data obtained in this way are of basic importance to the theories of Hull and Skinner, for example. Mr. Hurwitz reported experiments using a modified Skinner box (which he demonstrated) with which the temporal and serial patterning of responses (both at the food trough and the lever) could be observed. Analysis of results suggested that the postulation of a secondary drive, frustration, could best explain the behaviour of the rat during extinction of the habit. Evidence for this would not have been forthcoming if conventional methods of analysing responses had been used.

General discussions on the papers were introduced by Profs. R. W. Russell (London) and W. S. Verplanck (Harvard). There were detailed discussions on methodology of the individual researches reported; more general topics covered included behavioural differences between various strains of rats, the use of the concept 'abnormal', and the predictive value of learning theories.

B. M. Foss

\section{CAREERS IN CHEMICAL ENGINEERING}

A $N$ unexpected occurrence during the past few A years has been the large decline in the numbers of men seeking admission to the universities for training as engineers, a decline noted not only in Britain but also to an even greater extent in the United States. Simultaneously, committee after committee has urged the need for more engineers in general, and chemical engineers in particular. Extensive training schemes will obviously be of little value unless the numbers of those willing to be trained can be greatly increased, and thus the issue by the Institution of Chemical Engineers of a small brochure entitled "Careers in Chemical Engineering" is most opportune (pp. $12+4$ plates. Irist. Chem. Eng., 56 Victoria Street, I.ondon, S.W.1, 1953 ; 2s.). This explains clearly, in the simplest language, what chemical engineering is, how it developed, what a chemical engineer does, his opportunities, and how he can be trained; and it supplements its descrip. tions with admirable illustrations of plant of diverse nature, designed and constructed by chenical engineers. It is to be hoped that means will be found of bringing this pamphlet to the notice of every schoolboy leaving school, every schoolmaster, and every man at present engaged on National Service.

Modesty, unfortunately, seems to have compelled the authors to refrain from mentioning, except in the vaguest terms, the remuneration a chemical engineer may expect; in this materialistic age, one of the first questions asked by a young man selecting a career is: "What salary shall I get and what are the prospects ?" This aspect might well be amplified in a future edition. A further line of thought is aroused by the almost parenthetical mention of teaching as an outlet for chemical engineers. Every academic member of the profession knows only too well the extreme scarcity of good teachers, and this fact must be regarded at the moment as the bottleneck in any scheme for the large expansion of chemical engineering training in Britain. Until steps are taken to induce a far larger proportion of chemical engineers than at present to go in for teaching, any increase in the numbers seeking training, or in funds for laboratory extensions, will be rendered of little avail.

H. E. Watson

\section{WOOL INDUSTRIES RESEARCH ASSOCIATION}

\section{REPORT FOR 1952-53}

$T$ HE report for 1952-53 of the director of research of the Wool Industries Research Association* records that the opening of new research laboratories at the Leeds headquarters of the Association has greatly increased the research potential. Three new blocks of laboratory buildings, erected since the end of the Second World War, were officially opened by Lord Swinton in October last year. With a staff now totalling 203 , a very considerable variety of research topics has been and is being examined, ranging from $a d$ hoc investigations of a purely consultative type, designed to assist industrialists in solving the dayto-day problems of a highly technical industry, to almost purely mathematical analyses of the system of forces acting upon fibre arrays during roller drafting, and of the corresponding and resulting fibre displacements.

Among the many research activities mentioned in the director's report, several are noteworthy for the ingenuity and modernity of the techniques employed. For example, in order to test the theory of carding which has been developed at the Association, an electrical counterpart or analogue of the three-part scribbler has been built. This shows in electrical terms what happens to a discontinuous feed, such as is obtained from the hopper of a card, as it passes

* Wool Industries Research Association. Report of the Director of Association, Leeds, 1953.) 